Ingels, J., Vanreusel, A., Pape, E. et al. 2020. Ecological variables for deep-ocean monitoring must include microbiota and meiofauna for effective conservation. Nature Ecology \& Evolution

https://doi.org/10.1038/s41559-020-01335-6

\title{
Ecological variables for deep-ocean monitoring must include microbiota and meiofauna for effective conservation
}

Jeroen Ingels $^{1}{ }^{*}$, Ann Vanreusel ${ }^{2}$, Ellen Pape $^{2}$, Francesca Pasotti ${ }^{2}$, Lara Macheriotou ${ }^{2}$, Pedro Martínez Arbizu $^{3}$, Martin Vinther Sørensen ${ }^{4}$, Virginia P. Edgcomb ${ }^{5}$, Jyotsna Sharma ${ }^{6}$, Nuria Sánchez ${ }^{7}$, William B. Homoky $^{8}$, Clare Woulds ${ }^{8}$, Daniel Leduc ${ }^{9}$, Andrew J. Gooday ${ }^{10}$, Jan Pawlowski ${ }^{11,12}$, John R. Dolan ${ }^{13}$, Michaela Schratzberger $^{14}$, Sabine Gollner ${ }^{15}$, Alexandra Schoenle ${ }^{16}$, Hartmut Arndt ${ }^{16}$, Daniela Zeppilli ${ }^{17}$

ARISING FROM R. Danovaro et al. Nature Ecology \& Evolution https://doi.org/10.1038/s41559-019-1091-z (2020)

Recently, Danovaro et al. [1] prioritized deep-sea essential ecological variables (DEEVs), based on opinions from 112 deep-sea experts worldwide, to support development of a global deep-ocean monitoring and conservation strategy. While a set of universally important DEEVs is necessary to ensure appropriate monitoring, we challenge the conclusion that macro- and megafauna should be prioritized over microscopic organisms, notably eukaryotic and prokaryotic microbes, and meiofauna.

Status assessments of deep-sea habitats, and indeed any habitat, need to capture the most ecologically significant aspects, given current scientific understanding and existing methodologies. Danovaro et al.'s [1] claim that there is consensus among experts that deep-ocean monitoring should prioritize large organisms (macro- and megafauna) is partly a result of skewed expertise among survey respondents, 55\% of whom were macrofauna and megafauna experts. With the addition of expertise in fish and large vertebrates, the proportion of large-animal specialists increases to approximately $75 \%$ of respondents [1], leaving small, yet crucial, organisms, and associated processes, chronically underrepresented.

${ }^{1}$ Coastal and Marine Laboratory, Florida State University, St Teresa, FL, USA, ${ }^{2}$ Marine Biology Research Group, Ghent University, Gent, Belgium, ${ }^{3}$ DZMB, Senckenberg am Meer, Wilhelmshaven, Germany

${ }^{4}$ Natural History Museum of Denmark, University of Copenhagen, Copenhagen, Denmark

${ }^{5}$ Geology and Geophysics Department, Woods Hole Oceanographic Institution, Woods Hole, MA, USA

${ }^{6}$ Department of Biology, University of Texas at San Antonio, San Antonio, TX, USA, ${ }^{7}$ Department of Biodiversity, Ecology and Evolution, Faculty of Biological Sciences, Universidad Complutense de Madrid, Madrid, Spain, ${ }^{8}$ Faculty of the Environment, University of Leeds, Leeds, UK

${ }^{9}$ National Institute of Water and Atmospheric Research, Wellington, New Zealand, ${ }^{10}$ National Oceanography Centre, Southampton, UK, ${ }^{11}$ Department of Genetics and Evolution, University of Geneva, 1211 Geneva, Switzerland,

${ }^{12}$ Institute of Oceanology, Polish Academy of Sciences, 81-712 Sopot, Poland, ${ }^{13}$ Laboratoire d'Océanographie de Villefranche, CNRS \& Sorbonne Université, Villefranche-Sur-Mer, ${ }^{14}$ Centre for Environment, Fisheries and Aquaculture Science, Lowestoft, UK, ${ }^{15}$ Department of Ocean Systems, Royal Netherlands Institute for Sea Research, Texel, Netherlands, ${ }^{16}$ Biocenter, Institute for Zoology, General Ecology, University of Cologne, Cologne, Germany, ${ }^{17}$ LEP/EEP/REM, Institut Français de Recherche pour l'Exploitation de la MER, Plouzané, France, *Corresponding author: J. Ingels, jingels@fsu.edu, +1.850.697.4092 
It is unclear why macrofauna and megafauna were prioritized. Worth values and 'quasi' standard errors ('quasi' was not defined) substantially overlap (and the size of the error bars is remarkably consistent across variables within each DEEV component, cf. Fig. 2 in [1]), suggesting that meiofauna (organisms between ca. 20 and $1000 \mu \mathrm{m}$ ) are valued as important as megafauna. No statistically justified explanation is given for separating priority categories between meiofauna (medium) and megafauna (high).

Furthermore, the numbers reported in Danovaro et al. [1] do not correspond with previously published studies in favor of large organisms. The claim that $50-90 \%$ of large-sized species (e.g. cold-water corals and sharks) remain undiscovered is unsupported. It appears inconsistent with estimates that $39 \%$ of all deep-sea species, $23 \%$ of marine fish and $21-38 \%$ of hexacorals and octocorals are undescribed. In contrast, $88 \%$ of nematode species, the most abundant metazoan meiofauna phylum, remain undocumented [2].

Danovaro et al. [1] share our concerns regarding the importance of microorganisms by expressing surprise at the low to medium ranking of their biodiversity. The authors overturn the 'expert elicitation' results, highlighting that microbial heterotrophic and chemoautotrophic carbon production and elemental cycling are essential ecological variables to understand key processes that sustain the functioning of deep-sea food webs and biogeochemical cycles. Selectively overturning survey results, however, undermines the objectivity and validity of the study. The importance of meiofauna and microorganisms (bacteria, archaea, unicellular eukaryotes) in deep-sea ecosystems has repeatedly been highlighted [3-9], challenging the assumption that prioritization of larger organisms can meet deep-ocean monitoring requirements. Further conjectures [1] ascribe deep-sea energy transfer, carbon flow, and biomass mainly to large-sized animals (p 185), despite acknowledging the increasing importance of generally smaller fauna at greater depth. This point cannot be understated: we know that deep-sea microbial biomass is estimated between 10 and $30 \%$ of Earth's living biomass [5], and that meiofauna dominates metazoan biomass below 3000m [10]. Moreover, smaller organisms grow and reproduce much faster than larger organisms [11,12], and deep-sea benthic metabolism is largely driven by microorganisms $[9,13]$.

In developing conservation and monitoring goals, comparisons between marine and terrestrial ecosystems must be approached in the knowledge that, in many respects, they are fundamentally different. This applies particularly in deep-sea settings, where larger fauna are sparse and small organisms dominate biomass and diversity and are largely responsible for maintaining ecosystem function $[14,15]$. While conservation of more charismatic and larger organisms may pave the way for habitat protection, monitoring early change by establishing indicators or sentinels at the base of food webs and ecosystem functions, rather than among its end members, allows more efficient monitoring and timely conservation responses.

In valuing deep-sea ecosystem components for monitoring and conservation purposes, the complementarity of different monitoring tools, meaningful biological ecosystem elements and metrics of ecosystem health (e.g. EU Marine Strategy Framework Directive 2008/56/EC \& Decision 2017/848) must be taken into consideration. These elements respond differently to environmental change and stressors, and only an analysis of a representative set of ecological variables can produce a robust environmental assessment. Singling out certain components is not sufficient to make informed decisions. Instead, we would advocate an ecosystem-based approach that involves 1) research to support operational monitoring (incl. indicator development), 2) research to identify conservation priorities, and 3) research to generate the ecosystem understanding that supports both. Evidence-based conservation is imperative [16] and so should be the monitoring tools implemented to support it. It should also be noted that although related, conservation and monitoring are different: while conservation targets protection and measures to mitigate species, habitat, or the loss of ecosystem functions and services, monitoring involves the observation of patterns and processes over time, thus allowing detection of change using representative and sensitive system indicators. 
Meiofauna are well documented as sentinels for monitoring change in ecosystems worldwide [17,18], including the deep sea [19]. Their potential contribution to an effective and comprehensive deep-ocean monitoring strategy, however, is under-represented in Danovaro et al [1], particularly in light of rapidly advancing technologies such as quantitative or digital PCR, high-throughput sequencing (HTS) [20-22], and new imaging techniques [23]. These widely available and rapid sequencing methods for prokaryotes and protozoans, in particular, offer a rapid way to assess diversity and function, and monitor change [e.g. 24], and the same will apply for meiofauna in the near future [25]. The technology readiness level of these techniques are valued as low in [1], where acoustic, sonar, and imaging techniques dominate the actions proposed to monitor the most important DEEVs. However, current advances already allow for smallorganism monitoring and longer-term robust approaches should incorporate important current developments.

Protists are hardly mentioned by Danovaro et al. [1], even though they play diverse roles in many marine ecosystems $[12,26]$ by influencing deep-sea food webs and carbon nutrient pools directly and indirectly through ecological and trophic interactions $[27,28]$. Although small, naked protists (e.g. ciliates, flagellates, amoebae) and monothalamous foraminifera are difficult to study in deep-sea samples [29], new sequencing techniques are revealing an extraordinary diversity of novel lineages [30], which is valuable for deep-sea monitoring.

Globally, the deep ocean urgently needs sustainable conservation. Undervaluing the contribution of microscopic organisms to biodiversity and ecosystem functioning, and their efficiency in indicating and monitoring early change using latest technological developments, would hamper effective deep-sea management. Identifying variables for long-term, deep-sea monitoring must be driven by expert advice that encompasses balanced input from the broadest possible community of researchers and stakeholders. Without this, we cannot generate the knowledge necessary to adequately understand and protect the largest ecosystem on Earth.

\section{References}

1. Danovaro, R.; Fanelli, E.; Aguzzi, J.; Billett, D.; Carugati, L.; Corinaldesi, C.; Dell'Anno, A.; Gjerde, K.; Jamieson, A.J.; Kark, S., et al. Ecological variables for developing a global deep-ocean monitoring and conservation strategy. Nature Ecology \& Evolution 2020, 4, 181-192, doi:10.1038/s41559-019-1091-z.

2. $\quad$ Appeltans, W.; Ahyong, Shane T.; Anderson, G.; Angel, Martin V.; Artois, T.; Bailly, N.; Bamber, R.; Barber, A.; Bartsch, I.; Berta, A., et al. The Magnitude of Global Marine Species Diversity. Current Biology 2012, 22, 2189-2202, doi:http://dx.doi.org/10.1016/j.cub.2012.09.036.

3. Sogin, M.L.; Morrison, H.G.; Huber, J.A.; Welch, D.M.; Huse, S.M.; Neal, P.R.; Arrieta, J.M.; Herndl, G.J. Microbial diversity in the deep sea and the underexplored "rare biosphere". Proceedings of the National Academy of Sciences 2006, 103, 12115-12120.

4. Zeppilli, D.; Leduc, D.; Fontanier, C.; Fontaneto, D.; Fuchs, S.; Gooday, A.J.; Goineau, A.; Ingels, J.; Ivanenko, V.N.; Kristensen, R.M., et al. Characteristics of meiofauna in extreme marine ecosystems: a review. Marine Biodiversity 2018, 48, 35-71, doi:10.1007/s12526-017-0815-z.

5. Corinaldesi, C. New perspectives in benthic deep-sea microbial ecology. Frontiers in Marine Science 2015, 2, doi:10.3389/fmars.2015.00017.

6. $\quad$ Boeuf, D.; Edwards, B.R.; Eppley, J.M.; Hu, S.K.; Poff, K.E.; Romano, A.E.; Caron, D.A.; Karl, D.M.; DeLong, E.F. Biological composition and microbial dynamics of sinking particulate organic matter at abyssal depths in the oligotrophic open ocean. Proceedings of the National Academy of Sciences 2019, 116, 11824-11832, doi:10.1073/pnas.1903080116.

7. López-García, P.; Rodríguez-Valera, F.; Pedrós-Alió, C.; Moreira, D. Unexpected diversity of small eukaryotes in deep-sea Antarctic plankton. Nature 2001, 409, 603-607, doi:10.1038/35054537.

8. Schoenle, A.; Nitsche, F.; Werner, J.; Arndt, H. Deep-sea ciliates: Recorded diversity and experimental studies on pressure tolerance. Deep Sea Research Part I: Oceanographic Research Papers 2017, 128, 55 66, doi:https://doi.org/10.1016/j.dsr.2017.08.015.

9. Turley, C. Bacteria in the cold deep-sea benthic boundary layer and sediment-water interface of the NE Atlantic. FEMS Microbiology Ecology 2000, 33, 89-99, doi:10.1111/j.1574-6941.2000.tb00731.x. 
10. Wei, C.-L.; Rowe, G.T.; Escobar-Briones, E.; Boetius, A.; Soltwedel, T.; Caley, M.J.; Soliman, Y.; Huettmann, F.; Qu, F.; Yu, Z., et al. Global Patterns and Predictions of Seafloor Biomass Using Random Forests. Plos One 2010, 5, e15323.

11. Giere, O. Meiobenthology: the Microscopic Motile Fauna of Aquatic Sediments, $2^{\text {nd }}$ edition ed.; SpringerVerlag: Berlin, 2009; pp. 527.

12. Fenchel, T. Ecology of Protozoa: The biology of free-living phagotropic protists; Springer-Verlag: 2013.

13. Glud, R.N. Oxygen dynamics of marine sediments. Marine Biology Research 2008, 4, 243-289.

14. Nascimento, F.J.A.; Naslund, J.; Elmgren, R. Meiofauna enhances organic matter mineralization in soft sediment ecosystems. Limnology and Oceanography 2012, 57, 338-346, doi:10.4319/10.2012.57.1.0338.

15. Bonaglia, S.; Nascimento, F.J.A.; Bartoli, M.; Klawonn, I.; Brüchert, V. Meiofauna increases bacterial denitrification in marine sediments. Nat Commun 2014, 5, 5133, doi:10.1038/ncomms6133.

16. Sutherland, W.J.; Pullin, A.S.; Dolman, P.M.; Knight, T.M. The need for evidence-based conservation. Trends in Ecology \& Evolution 2004, 19, 305-308, doi:https://doi.org/10.1016/j.tree.2004.03.018.

17. Balsamo, M.; Semprucci, F.; Frontalini, F.; Coccioni, R. Meiofauna as a tool for marine ecosystem biomonitoring. In Marine Ecosystems, Cruzado, A., Ed. InTech Publisher: 2012; pp. 77-104.

18. Schratzberger, M.; Ingels, J. Meiofauna matters: The roles of meiofauna in benthic ecosystems. Journal of Experimental Marine Biology and Ecology 2018, 502, 12-25, doi:10.1016/j.jembe.2017.01.007.

19. Zeppilli, D.; Sarrazin, J.; Leduc, D.; Arbizu, P.M.; Fontaneto, D.; Fontanier, C.; Gooday, A.J.; Kristensen, R.M.; Ivanenko, V.N.; Sørensen, M.V., et al. Is the meiofauna a good indicator for climate change and anthropogenic impacts? Marine Biodiversity 2015, 45, 505-535, doi:10.1007/s12526-015-0359-z.

20. Carugati, L.; Corinaldesi, C.; Dell'Anno, A.; Danovaro, R. Metagenetic tools for the census of marine meiofaunal biodiversity: An overview. Marine Genomics 2015, 24, 11-20, doi:https://doi.org/10.1016/j.margen.2015.04.010.

21. Danovaro, R.; Carugati, L.; Berzano, M.; Cahill, A.E.; Carvalho, S.; Chenuil, A.; Corinaldesi, C.; Cristina, S.; David, R.; Dell'Anno, A., et al. Implementing and Innovating Marine Monitoring Approaches for Assessing Marine Environmental Status. Frontiers in Marine Science 2016, 3, doi:10.3389/fmars.2016.00213.

22. Dell'Anno, A.; Carugati, L.; Corinaldesi, C.; Riccioni, G.; Danovaro, R. Unveiling the Biodiversity of Deep-Sea Nematodes through Metabarcoding: Are We Ready to Bypass the Classical Taxonomy? PLOS ONE 2015, 10, e0144928, doi:10.1371/journal.pone.0144928.

23. Kitahashi, T.; Watanabe, H.K.; Tsuchiya, M.; Yamamoto, H.; Yamamoto, H. A new method for acquiring images of meiobenthic images using the FlowCAM. MethodsX 2018, 5, 1330-1335, doi:https://doi.org/10.1016/j.mex.2018.10.012.

24. Pawlowski, J.; Esling, P.; Lejzerowicz, F.; Cedhagen, T.; Wilding, T.A. Environmental monitoring through protist next-generation sequencing metabarcoding: assessing the impact of fish farming on benthic foraminifera communities. Molecular Ecology Resources 2014, 14, 1129-1140, doi:10.1111/17550998.12261 .

25. Bik, H.M.; Porazinska, D.L.; Creer, S.; Caporaso, J.G.; Knight, R.; Thomas, W.K. Sequencing our way towards understanding global eukaryotic biodiversity. Trends in Ecology \& Evolution 2012, 27, 233-243, doi:http://dx.doi.org/10.1016/j.tree.2011.11.010.

26. Fenchel, T. The ecology of marine microbenthos IV. Structure and function of the benthic ecosystem, its chemical and physical factors and the microfauna commuities with special reference to the ciliated protozoa. Ophelia 1969, 6, 1-182, doi:10.1080/00785326.1969.10409647.

27. Worden, A.Z.; Follows, M.J.; Giovannoni, S.J.; Wilken, S.; Zimmerman, A.E.; Keeling, P.J. Rethinking the marine carbon cycle: factoring in the multifarious lifestyles of microbes. Science 2015, 347, 1257594.

28. Gooday, A.J.; Schoenle, A.; Dolan, J.R.; Arndt, H. Protist diversity and function in the dark ocean Challenging the paradigms of deep-sea ecology with special emphasis on foraminiferans and naked protists. European Journal of Protistology 2020, 75, 125721, doi:https://doi.org/10.1016/j.ejop.2020.125721.

29. Schoenle, A.; Jeuck, A.; Nitsche, F.; Venter, P.; Prausse, D.; Arndt, H. Methodological studies on estimates of abundance and diversity of heterotrophic flagellates from the deep-sea floor. Journal of Marine Science and Engineering 2016, 4, 22.

30. Lecroq, B.; Lejzerowicz, F.; Bachar, D.; Christen, R.; Esling, P.; Baerlocher, L.; Østerås, M.; Farinelli, L.; Pawlowski, J. Ultra-deep sequencing of foraminiferal microbarcodes unveils hidden richness of early monothalamous lineages in deep-sea sediments. Proceedings of the National Academy of Sciences 2011, 108, 13177-13182, doi:10.1073/pnas.1018426108. 


\section{Acknowledgements}

H.A. was supported by the German Research Foundation (grant numbers AR 288/23, MerMet 17-97 and MerMet 71-11). We thank R. Danovaro et al. for an open exchange of ideas during the preparation of this Matters Arising.

\section{Author contributions}

J.I., D.Z. and A.V. initiated the Matters Arising. J.I. led the writing and all authors contributed to the writing and the development of the Matters Arising and its final form. J.I. produced the final agreed edited version.

\section{Competing interests}

The authors declare no competing interests.

\section{Additional information}

Correspondence and requests for materials should be addressed to J.I. 